\title{
Design of Single Stage Axial Turbine for Mini Turbojet Engine
}

\author{
I Syarafina ${ }^{1}$, P Adnan', and F Hartono ${ }^{1, *}$ \\ 1 Faculty of Mechanical and Aerospace Engineering, Institut Teknologi Bandung, Labtek II Building, \\ Jl. Ganesa 10 Bandung 40132 \\ * Correspondence: firman7738@yahoo.com
}

Received: 18 February 2020; Accepted: 25 May 2020; Published: 30 June 2020

\begin{abstract}
This paper explains about aerodynamic design of a single stage gas generator turbine for a small turbojet engine. The design requirement is that the turbine must be able to deliver power output of $150 \mathrm{~kW}$ at $0.814 \mathrm{~kg} / \mathrm{s}$ gas mass flow, with turbine inlet temperature of $1200 \mathrm{~K}$, and turbine inlet pressure of $267508 \mathrm{~Pa}$. The design phase consists of 4 steps, which is thermodynamic property analysis using parametric cycle analysis, determination of velocity triangle in $2 \mathrm{D}$ plane and $2 \mathrm{D}$ blade design using CASCADE software, 3D geometry modeling, and 3D flow analysis at design point using Computational Fluid Dynamics method. In parametric cycle analysis, design points are applied to get the unknown thermodynamics property. The determination of velocity triangles, two conditions are applied: zero inlet swirl and constant nozzle angle design. The design continues with the 2D approach in CASCADE to determine the airfoil type at the hub, mean, and the tip of the blade based on the inlet and outlet flow conditions. The 3D approach flow analysis is done by simulating the 3D geometry that has been made using CAD in full configuration to evaluate the overall performance of the turbine, especially the power generated by the turbine. The observed parameters are clearance, stagger angle, and cambered flat plate substitution in NGV affects the turbine's output power. The analysis results show that all of those parameters above affect the turbine's output power in a different way from one to each other. The bigger the clearance, the power output and the efficiency that is generated by the turbine also become bigger. Same as clearance, the stagger angle of turbine's NGV also affects the turbine power and efficiency. The bigger the stagger angle, the bigger the power, but the efficiency drops.
\end{abstract}

Keywords: zero inlet swirl, constant nozzle angle, parametric cycle analysis

\section{Introduction}

In this growing era, the need for energy will continue to increase along with the development of technology. One of the tools that can be used to process the energy is turbine. There are small turbines as used for Unmanned Aerial Vehicle (UAV) [1]. In the design of turbojet engine, the turbine must be able to sustain the high temperature from the heated air in combustion chamber. In designing a good turbine, we need to pay attention to various aspects including the ease of manufacturing and the production costs. If the turbine is well designed and efficient, but difficult to manufacture, then production cost will raise up. Therefore, it would be nice if the turbine is designed with a low level of manufacturing difficulty without reducing the performance of the turbine. Along with technological developments, the turbine design process can now be done by using computational methods, namely with computational fluid dynamics (CFD) [2,3]. With CFD the flow that enters and exits the turbine can be simulated so that designing a turbine will be more detailed than just using the analytical method. 


\section{Materials and Methods}

The design point of the turbine is summarized below. The design method has been explained before in the abstract part. There are four steps needed to design the turbine, which is thermodynamic property analysis using parametric cycle analysis, determination of velocity triangle in 2D plane and 2D blade design using CASCADE software, 3D geometry modeling, and 3D flow analysis at design point using Computational Fluid Dynamics method. Below is the design point of the turbine as follow.

$\begin{array}{ll}\text { Mass Flow (m) } & : 0.814 \mathrm{~kg} / \mathrm{s} \\ \text { Turbine Inlet Temperature (TiT) } & : 1200 \mathrm{~K} \\ \text { RPM } & : 75000 \mathrm{rev} / \text { minute } \\ \text { CPR } & : 3.67 \\ \text { Mass flow fuel }(\dot{\mathrm{m} f}) & : 0.01723 \mathrm{~kg} / \mathrm{s} \\ \text { Efficiency of Nozzle }(\eta \mathrm{n}) & : 90 \% \\ \text { Efficiency of Turbine }(\eta \mathrm{t}) & : 70 \% \\ \text { Efficiency of Mechanic }(\eta \mathrm{m}) & : 99 \% \\ \text { Efficiency of Compressor }(\eta \mathrm{c}) & : 67.1 \%\end{array}$

The following are the brief explanation of the steps from the analytical method that is used, the numerical method (CFD Simulation) will be explained in point 3.

\subsection{Parametric cycle Analysis}

Parametric cycle analysis is a method for determining the thermodynamic properties at the design points. For turbojet engines, parametric cycle analysis is carried out referring to the Brayton cycle.

\subsection{Determination of Velocity Triangle and Blading Design}

To determine the velocity triangle, there are some assumptions that is used to simplify the process. The assumption that is the zero-inlet swirl. Zero inlet swirl assumes that the flow that enter and exits the stator and rotor blades are in 0 degrees (enters and exit horizontally).

Just like the velocity triangle determination, the blading design also has assumption that's used to simplify the process. The assumption is constant nozzle angle design. Constant nozzle angle design is a method to design the blade which assume that there is no twist in the blade and the profile of the blade in hub, mean, tip is the same.

The following are the detail calculation to derive the flow angle in the turbine blade section (hub, mean, tip) to determine the flow angle (alpha-2, alpa-3, beta-2, beta-3). The first thing to determine is the work coefficient $(\psi)$ and the flow coefficient $(\phi)$ by using these formulas [4].

$$
\begin{aligned}
& \psi=\frac{\Delta h_{\mathrm{g}}}{U^{2}} \\
& \phi=\frac{c_{x}}{U}
\end{aligned}
$$

Where

$$
\Delta h_{0}=\frac{\gamma R}{\gamma-t}\left(T_{t 4}-T_{t 5}\right)
$$

By doing some mathematic manipulation, the flow angle can be determined as follows. 


$$
\begin{aligned}
& \alpha_{2}=\tan ^{-1}\left(\frac{\psi}{\phi}\right) \\
& \beta_{2}=\tan ^{-1}\left(\frac{\psi-1}{\phi}\right) \\
& \beta_{3}=\tan ^{-1}\left(\frac{1}{\phi}\right)
\end{aligned}
$$

The velocity of the flow can be determined by using the formula which is derivate from the constant nozzle angle formula below.

$$
\begin{gathered}
C_{a} \frac{d C_{a}}{d r}+C_{w} \frac{d C_{w}}{d r}+\frac{C_{w}^{3}}{r}=\frac{d h_{0}}{d r} \\
\frac{C_{a s}}{C_{w 2}}=\cot \alpha_{2}=\text { constant } \\
C_{w 2} r^{\sin ^{2} \alpha 2}=\text { constant } \\
C_{a 2} r^{\sin ^{2} \alpha 2}=\text { constant } \\
C_{a 2} m=C_{a 3} m=C_{w 2} m \cot \alpha_{2}
\end{gathered}
$$

After having the velocity triangle, the next step is to choose the blade design for both stator and rotor. For stator, we assume that the profile is same for the mean, hub, and tip of the blade (constant nozzle angle). Meanwhile, for the rotor we do not assume that. The important aspect to determine the turbine blade design is the airfoil maximum camber location, camber angle theta, stagger angle, pitch chord ratio, and airfoil profile thickness. Those variables need to be arranged so the shock free condition is obtained. The airfoil that is used in the design process is NACA 0012 due to its simple geometry.

\subsection{Geometry Modelling}

The geometry is modeled as 3-dimensional model. The model of the turbine is shown in the figure below, which the diameter is about $10 \mathrm{~cm}$

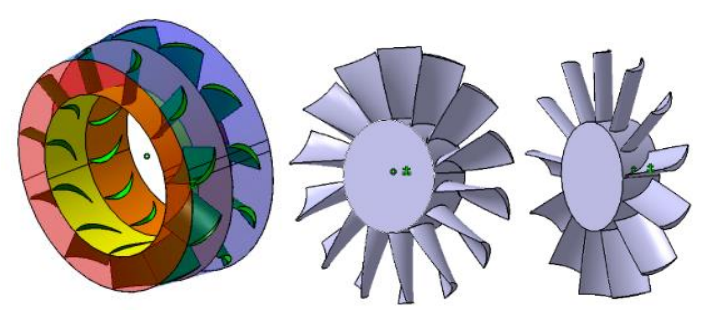

Figure 1. Geometry of the turbine.

The simulation is done by CFD simulation. The boundary domain is divided into two domain, namely stationary domain (contains inlet, stator hub, stator shroud, and stator blade) and boundary domain (contains outlet, rotor hub, rotor shroud, and rotor blade). The boundary then set into the desired value which already obtained from PCA, also already determined in DR\&O. The last step in the simulation is running convergence check. 


\section{Results and Discussions}

\subsection{Design Result}

The turbine which is designed with $0.5 \mathrm{~mm}$ clearance and stagger angle of $39.2^{\circ}$ can derive power of $157 \mathrm{~kW}$ with $89.7 \%$ efficiency.

\subsection{Clearance Effect}

To know the clearance effects to the power derived by the turbine, the clearance gap is varied into 3 variation which is the initial design $(0.5 \mathrm{~mm}), 1 \mathrm{~mm}$, and $0.4 \mathrm{~mm}$. The result shown in the Figure 2.

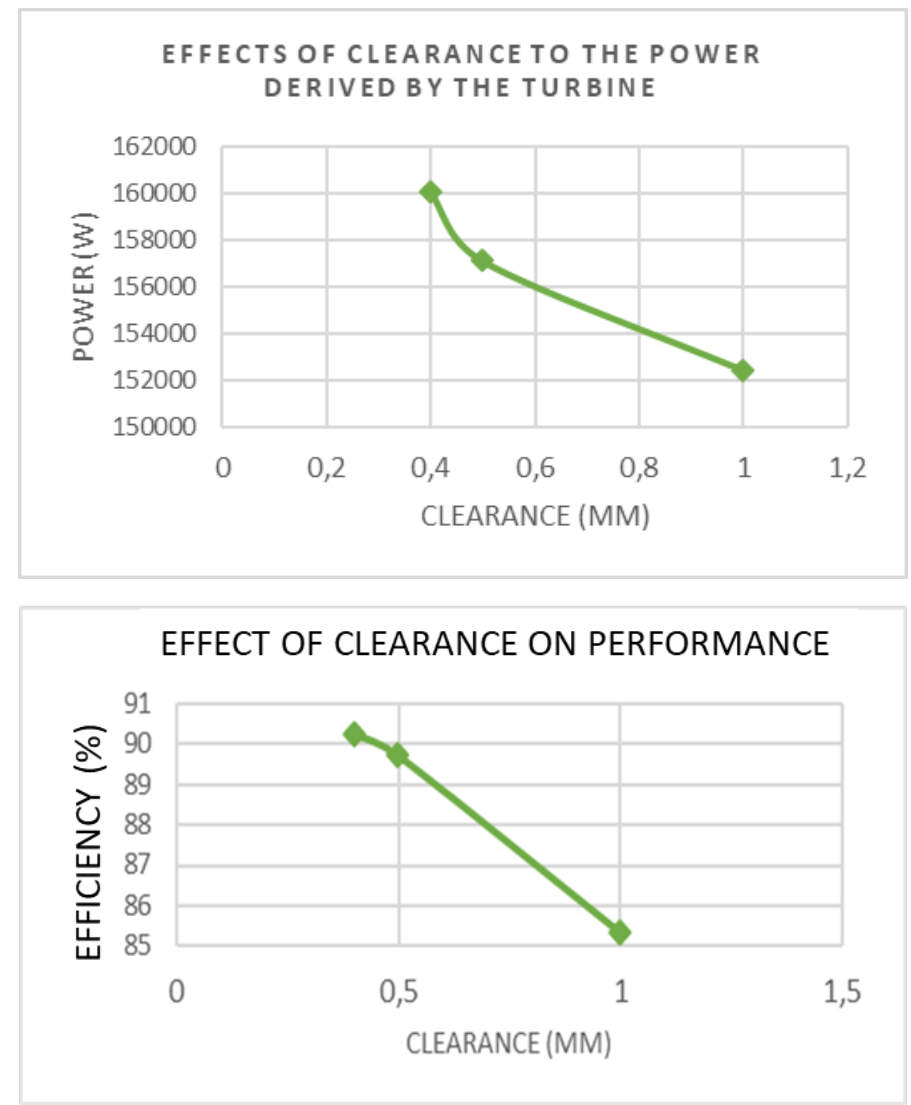

Figure 2. Effects of clearance to turbine performance.

The greater the tip clearance, then the power produced by the turbines become smaller. Tip clearance needs to be designed in such a way so the power of the turbine is sufficient with good efficiency. Ideally, the smaller the clearance tip between rotor blades and rotor shroud, the power output is also become higher. However, tip clearance distance which is too small causes an increase in pressure in the inlet area of the turbine. Addition to that, the clearance tip distance that is too small is difficult to manufacture, so it will increase the cost [5].

\subsection{Stagger Angle Effect}

This paper also explains about the stagger angle effects to the turbine power output. Below are the results of stagger angle effects on turbine power output as well as turbine efficiency. 

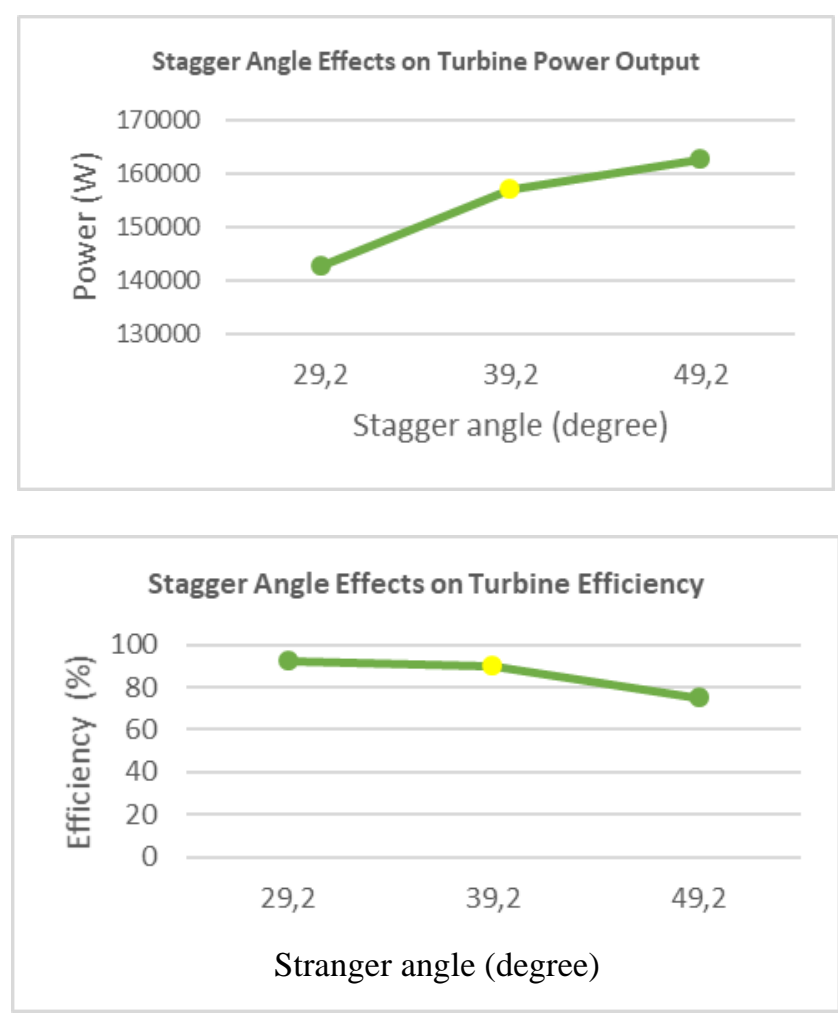

Figure 3. Stagger angle effects

Along with the increasing stagger angle, the smaller the area between the NGV blades, so the inlet pressure gets bigger too. This is followed by the decrease in turbine efficiency.

\subsection{Bended Flat Plat Design in NGV}

Beside designing the NGV blade using the airfoil, we also do the research about the flat plate design in NGV blade. The flat plate is obtained by bending the flat plate into the mean chamber line of the airfoil, which is NACA 0012. Having clearance of $0.5 \mathrm{~mm}$ and NGV stagger angle of $39.2^{\circ}$, the flat plate turbine design can deliver power output in the amount of $155 \mathrm{~kW}$ with the efficiency of $89 \%$. The difference of the power output from the turbine with airfoil blade and the turbine with flat plate is about $1.27 \%$ where the airfoil turbine delivers more power than the flat plate turbine. But this method can be an option if we want to design the more simple turbine with the easier manufacturing process as presented by others [6,7].

\section{Conclusions}

The turbine we designed can derive the power of $157 \mathrm{~kW}$ with $89 \%$ efficiency. To change the power output of the turbine, there is no need to change the airfoil type, it can be done by changing the stagger angle and the clearance gap. The smaller the clearance, the higher the turbine power output, also the efficiency. But, the ease of manufacturing should be considered. The higher the stagger angle, the higher the turbine power output, but the efficiency decrease.

\section{References}

1. Lewis, Turbomachinery Performance Analysis, Elsevier Science \& Technology, 1996

2. H. Cohen, Gas Turbine Theory, Longman Group Limited, 1996

3. Jack D. Mattingly, Elements of Propulsion: Gas Turbines and Rockets, AIAA Education Series,1989 
4. Anderson Jr., John D., Fundamental of Aerodynamics, McGraw-Hill Series

5. Hartono, Firman, Aero Propulsion Presentation Chapter Axial Turbine

6. Hartono, Firman, Aircraft Propulsion Chapter Parametric Cycle Analysis

7. Hartono, Firman, Aircraft Propulsion Chapter Turbomachinery

(c) (1)

This is an open-access article distributed under the terms of the Creative Commons Attribution 4.0 International License, which permits unrestricted use, distribution, and reproduction in any medium provided the original work is properly cited. 